EPiC Series in Engineering
Volume 3, 2018, Pages 2425-2432
HIC 2018. 13th International
Conference on Hydroinformatics

\title{
Numerical Simulation of Overland Flows Using Godunov Scheme Based on Finite Volume Method
}

\author{
Dawei Zhang ${ }^{1 *}$,Jin Quan ${ }^{1}$,Zhili Wang ${ }^{2}$, Hongbin Zhang ${ }^{1}$ and Jianming Ma ${ }^{1}$ \\ ${ }^{1}$ China Institute of Water Resources and Hydropower Research, Beijing, China \\ ${ }^{2}$ Nanjing Hydraulic Research Institute, Nanjing, China \\ 40978552 @qq. Com, $122178130 @ \mathrm{gq} . \mathrm{Com}$, \\ 965753441 @qq. com, 164531000 @qq . com, $1091764300 @ q q \cdot c o m$
}

\begin{abstract}
A new numerical model for simulating overland flows has been developed using Godunov scheme based on the two-dimensional fully dynamic shallow water equations (SWEs). There are a number of frequently and partially submerged cells due to steep slopes, coarse meshes and small depth when simulating the surface runoff propagation, which are different from the original hydraulic applications such as flooding. In order to provide an accurate numerical solution for overland flows, the model in this work uses the Roe's approximate Riemann solver for the calculation of fluxes on the triangulated unstructured grid based on the flow sheet regime, and the bottom slope terms are calculated directly by applying the Green's theorem. To control the global stability of the model, the semi-implicit discretization method is adopted to deal with the highly nonlinear friction terms. The new model provides more comprehensive calculation capabilities, which are proved by several case studies, and the numerical results match well with analytical solutions, experimental data or results computed by other numerical models.
\end{abstract}

\section{Introduction}

Surface runoff is a dynamic response of the catchment from rainfall, and it is quite often associated with a sudden rise of the stream hydrograph in small hilly or mountainous catchments (e.g. those of less than $200 \mathrm{~km}^{2}$ ). Furthermore, due to the climate change, this type of flood event has occurred more frequently than ever before, and is frequently connected with severe damages. In order to obtain detailed hydraulic information associated with extreme flood events, numerical models based on 2D shallow water equations is becoming more and more popular [1-3]. Unlike fluvial floods

${ }^{*}$ Corresponding author 
or dam-break floods in which the inundation areas are usually confined within the floodplain of a river channel and the wet/dry front is relatively easy to be identified, pluvial floods usually involve very shallow flows on steep slopes and the wet/dry front may be widely distributed. Therefore, how to discretize slope source terms for simulating very shallow flows over steep and irregular slopes has become a great challenge. Many researchers have focused on this problem and numerous numerical schemes have been developed to deal with the bed slope source terms [4-6]. Another challenge for developing a robust overland flow model based on the fully SWEs is related to the discretization of friction source terms. Many effective schemes have also been reported in the literature and the implicit or semi-implicit treatment of the friction source term is most widely applied [3,7].

In this paper, a new numerical model solving the SWEs for overland flow simulation is presented to address the aforementioned challenges. The model was then verified using several classical test cases, in which the numerical results agree closely with analytical solutions or experimental measurements.

\section{Numerical Model Development}

\subsection{Governing Equations}

The $2 \mathrm{D}$ shallow water equations in conservative form are written as

$$
\frac{\partial U}{\partial t}+\nabla \cdot F=\frac{\partial U}{\partial t}+\frac{\partial E}{\partial x}+\frac{\partial G}{\partial y}=S
$$

Where $U, F, E, G$ and $S$ are, respectively, the column vector of the conserved variables, the flux vector, the flux components in the $\mathrm{x}$ and $\mathrm{y}$ directions, and the source term, defined as follows:

$$
U=\left[\begin{array}{l}
h \\
h u \\
h v
\end{array}\right], F=E \vec{i}+G \vec{j}, E=\left[\begin{array}{c}
h u \\
h u^{2}+\frac{g h^{2}}{2} \\
h u v
\end{array}\right], G=\left[\begin{array}{c}
h v \\
h u v \\
h v^{2}+\frac{g h^{2}}{2}
\end{array}\right], S=\left[\begin{array}{c}
r \\
g h\left(S_{o x}-S_{f x}\right) \\
g h\left(S_{o y}-S_{f y}\right)
\end{array}\right]
$$

Where $h=$ water depth, $u$ and $v=$ the $x$ and $y$ velocity components; $\mathrm{g}=$ the gravitational acceleration; $r$ =rainfall rate; $S_{o x}, S_{o y}$ and $S_{f x}, S_{f y}=$ Cartesian components of bed and friction slope, respectively, given as

$$
S_{o x}=-\frac{\partial Z_{b}}{\partial x}, S_{o y}=-\frac{\partial Z_{b}}{\partial y}, S_{f x}=\frac{n^{2} u \sqrt{u^{2}+v^{2}}}{h^{4 / 3}}, S_{f y}=\frac{n^{2} v \sqrt{u^{2}+v^{2}}}{h^{4 / 3}}
$$

Where $Z_{b}=$ bed elevation, $n=$ Manning's roughness coefficient.

\subsection{Numerical Discretization}

A cell-centered finite-volume approach based on triangular unstructured mesh is used. Integrating Eq. (1) over an arbitrary cell $V$, and applying the Gauss Theorem gives

$$
\Delta U=-\frac{\Delta t}{A} \sum_{j=1}^{m}\left(F_{j}^{*} \cdot n_{j}\right) l_{j}+\frac{\Delta t}{A} \int_{V} S d V
$$

Where $\Delta U=$ the variation of the averaged value of $U$ over the cell in the time interval; $A=$ the area of the cell; $m=$ the number of sides of the cell; $l_{j}=$ the cell side length; $n_{j}=$ outward pointing unit normal vector; $F^{*}=$ numerical flux function. 


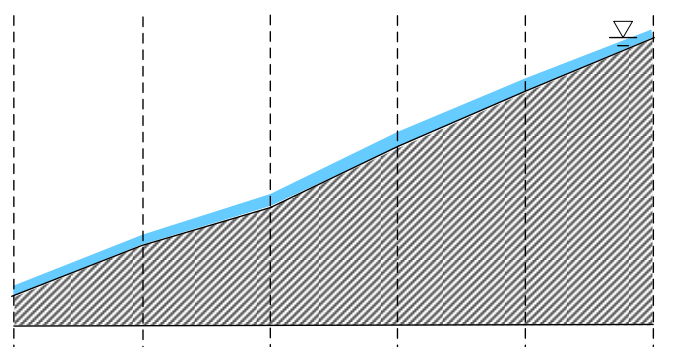

Figure 1: Sheet flow regime of overland flow for hydrological applications

Overland flow is characterized by the process of a thin sheet of runoff movement over a steep slope as shown in Fig.1. A sheet flow concept found by Kim et al(2012) is used for modelling purpose in which cell-centred depths only are used in solving the flow equations and the bed slope source is discretized directly using Eq.(5) [8].

$$
S_{o x}=-\frac{\left(y_{2}-y_{0}\right)\left(z_{1}-z_{0}\right)-\left(y_{1}-y_{0}\right)\left(z_{2}-z_{0}\right)}{\left(y_{2}-y_{0}\right)\left(x_{1}-x_{0}\right)-\left(y_{1}-y_{0}\right)\left(x_{2}-x_{0}\right)} S_{o y}=-\frac{\left(x_{2}-x_{0}\right)\left(z_{1}-z_{0}\right)-\left(x_{1}-x_{0}\right)\left(z_{2}-z_{0}\right)}{\left(x_{2}-x_{0}\right)\left(y_{1}-y_{0}\right)-\left(x_{1}-x_{0}\right)\left(y_{2}-y_{0}\right)}
$$

Where the subscripts 0,1 and 2 are three counter-clockwise vertices of a cell.

The numerical flux is given by Roe's method:

$$
F^{*} \cdot n=\frac{1}{2}\left[(E, G)_{R} \cdot n+(E, G)_{L} \cdot n-|\bar{J}|\left(U_{R}-U_{L}\right)\right]+\left[0, \frac{1}{24} g(\Delta h)^{2} \cos \alpha, \frac{1}{24} g(\Delta h)^{2} \sin \alpha\right]^{T}
$$

Where $\bar{J}=$ the Roe's average Jacobian matrix. Subscripts $R$ and $L$ are referred to the right and left side of the cell interface, respectively. $\alpha$ is the angle between the face normal vector and the $x$-axis, measured in the anticlockwise direction. $\Delta h$ is the difference in depth as evaluated between the adjacent vertices of the cell's face. The second vector represents a pressure correction and one can refer to Warnock et al (2014) for details [9].

A semi-implicit expression in time is used to deal with the slope friction source terms and the equation is as follows:

$$
g h S_{f x}=\left(\frac{n^{2} g \sqrt{u^{2}+v^{2}}}{h^{4 / 3}}\right)^{n}(h u)^{n+1}, g h S_{f y}=\left(\frac{n^{2} g \sqrt{u^{2}+v^{2}}}{h^{4 / 3}}\right)^{n}(h v)^{n+1}
$$

\section{Model Verification}

\subsection{Variable Rainfall over a One-dimensional Slope}

Three cases are simulated which consider rainfall change in time, proposed by Govindaraju et al (1990) [10] and used by Gottardi and Venutelli(2008) [11], Liang et al (2015)[12]. The plane has a length $L=21.945 \mathrm{~m}$. The value of Chézy roughness coefficient $C=1.336 \mathrm{~m}^{1 / 2} / \mathrm{s}$ in case 1 and $C=1.767$ $\mathrm{m}^{1 / 2} / \mathrm{s}$ in case 2 and case 3 . The slope $S=0.001$ in case 1 and $S=0.04$ in case 2 and case 3 . The input rainfall series in three cases are given in Table 1.

The simulated hydrographs for the three cases are shown in Fig.2. The simulation results agree very well with the approximated analytical solutions given by Govindaraju et al. (1990) [10]. From the Fig. 2 we can see that both the peak runoff and the overall shape match well with the analytical solutions. Similar results were also presented in Gottardi and Venutelli(2008) [11], which solved a diffusive wave and a kinematic wave model. Liang et al (2015) used a TVD-MacCormack scheme to simulate the rainfall-runoff process of case 2 and case 3 [12]. 


\begin{tabular}{cccccc}
\hline Time $(\min )$ & $0-10$ & $10-20$ & $20-30$ & $30-40$ & $\ldots \ldots$ \\
\hline Rainfall in case $1\left(10^{-5} \mathrm{~m} / \mathrm{s}\right)$ & 2.82222 & 1.41111 & 2.82222 & 1.41111 & 0 \\
Rainfall in case $2\left(10^{-5} \mathrm{~m} / \mathrm{s}\right)$ & 1.41111 & 2.82222 & 1.4111 & 2.82222 & 0 \\
Rainfall in case $3\left(10^{-5} \mathrm{~m} / \mathrm{s}\right)$ & 2.82222 & 1.41111 & 2.82222 & 1.41111 & 0 \\
\hline
\end{tabular}

Table 1: Rainfall rate for three test cases

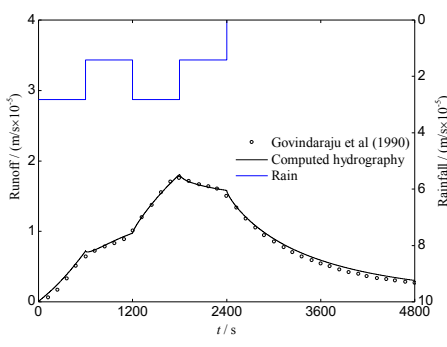

(a) case 1

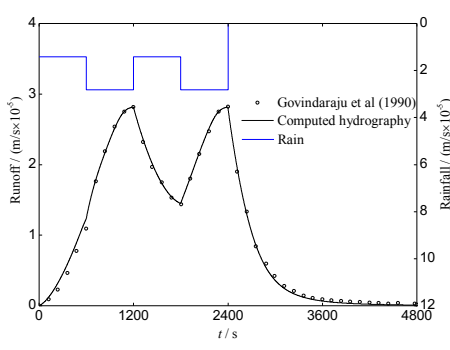

(b) case 2

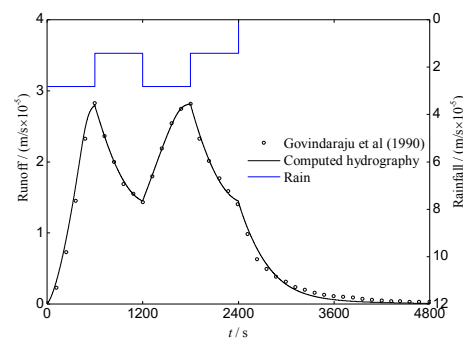

(c) case 3

Figure 2: Hydrographs of variable rainfalls over a one-dimensional slope

\subsection{One-dimensional Flow Over a Mild-sloped Plane}

A simple test case of one-dimensional flow over an inclined mild-sloped plane with a length of $200 \mathrm{~m}$ caused by an uniform rainfall $r=60 \mathrm{~mm} / \mathrm{h}$ for $t=1 \mathrm{~h}$ is used herein to validate the model, which is proposed by Gottardi and Venutelli(2008) [11], and also used by Kim et al(2012) [8]. The bed slope of the plane is 0.001 and the Manning's coefficient is $0.03 \mathrm{~m}^{-1 / 3} \mathrm{~s}$. From the analytical solution of the kinematic-wave problem, the time of concentration is $31.62 \mathrm{~min}$; the unit discharge at steady state conditions is $0.00333 \mathrm{~m}^{2} / \mathrm{s}$ and the corresponding flow depth is $0.0316 \mathrm{~m}$. The triangular unstructured mesh spacing is $5.0 \mathrm{~m}, 1.0 \mathrm{~m}$ and $0.5 \mathrm{~m}$, respectively. Fig. 3 shows the simulated hydrograph at the downstream boundary as well as a comparison with the kinematic analytical solution. Overall, the presented numerical solution agrees well with the kinematic analytical solution and the timing and magnitude of the rising and falling limbs are satisfactory. It is also found that the numerical solutions are generally closer to the analytical solution when finer mesh is used. Particularly, the attenuation effects in the rising limb occurred, which is also found by Gottardi \& Venutelli(2008) [11] and Kim et $\operatorname{al}(2012)[8]$.

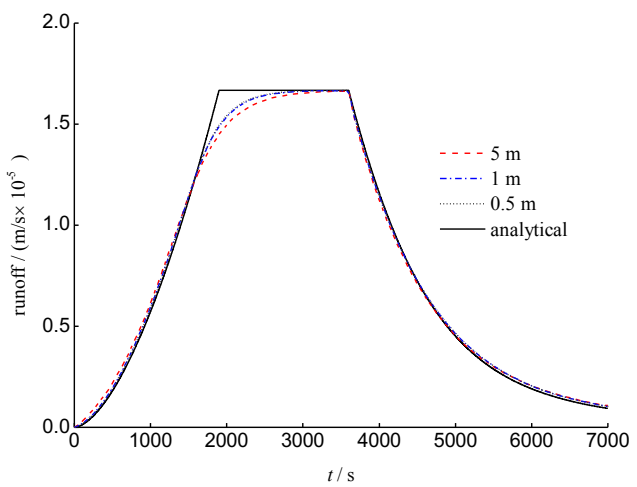

Figure 3: Runoff hydrograph for simulated solution and analytical solution 


\subsection{Rainfall Over a Two-dimensional Experimental Catchment}

The laboratory experiment was completed by Cea et al (2008) [13] to study the shallow water flow generated by a uniform rainfall over a simple two-dimensional geometry. The physical model consists of 3 stainless steel planes, each of them with a slope of 0.05 , which are connected to form a $2 \mathrm{~m} \times 2.5 \mathrm{~m}$ rectangular basin, as seen in Fig.4. To increase the time of concentration, two oblique high walls are added to the basin, which are indicated by the thick white lines in Fig.4. Rainfall is simulated with a grid of 100 nozzles distributed over the entire basin and the outlet hydrograph is measured, which will be used to validate the presented numerical model. Herein, the Manning's coefficient is $0.009 \mathrm{~m}^{-1 / 3} \mathrm{~s}$.

Three scenarios with different rainfall intensity have been investigated. In the first case, the rainfall intensity is $317 \mathrm{~mm} / \mathrm{h}$ during $45 \mathrm{~s}$. In the second case, $320 \mathrm{~mm} / \mathrm{h}$ rainfall is applied for $25 \mathrm{~s}$, stopped for $4 \mathrm{~s}$, and reapplied for another $25 \mathrm{~s}$. The last case is similar to the second case, but the rainfall stopped for $7 \mathrm{~s}$ and the intensity of the rainfall is $328 \mathrm{~mm} / \mathrm{h}$.

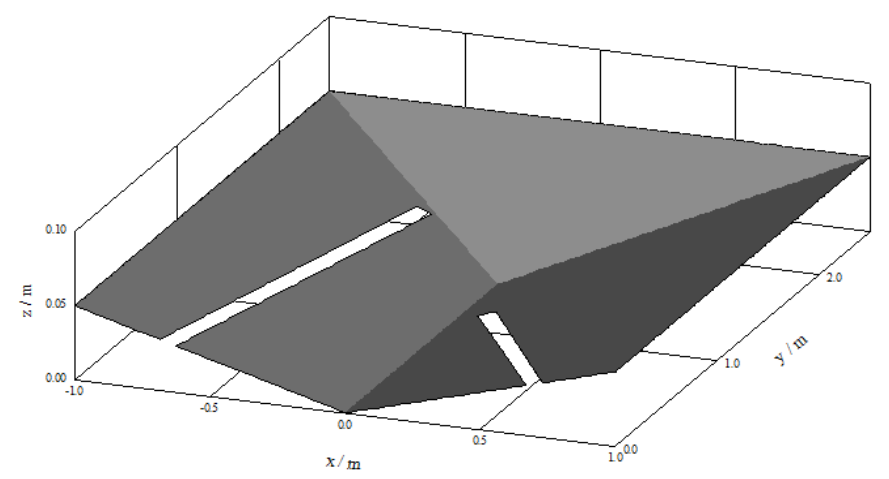

Figure 4: 3D view of the catchment shape studied in Cea et al (2008)

The triangular mesh is used to model the experiments and the the average element size of the mesh is $0.02 \mathrm{~m}$ ( 28196 unstructured cells in total over a surface of $\left.5 \mathrm{~m}^{2}\right)$. At the outlet boundary, the flow undergoes a free fall after running out of the domain and the solid wall condition is specified at the other three boundaries.

Fig.5 illustrates three snapshots of the water depth distribution and velocity fields in three cases. The simulations are found to be rational because of the good match with real situation. The simulations and experiments hydrographs for all three cases are plotted in Fig.6, together with the corresponding hyetographs. The shape of the hydrograph is very well simulated in all cases, as well as the peak discharge and it is also similar to the numerical results carried out by Cea et al(2008) [13], where a few experimental uncertainties were pointed out that might cause the deviation between the measured and predicted results. For example, the tail of the hydrograph is slightly underestimated by the numerical model. This is probably due to the fact that some nozzles still leaks a bit after the rainfall stops. 


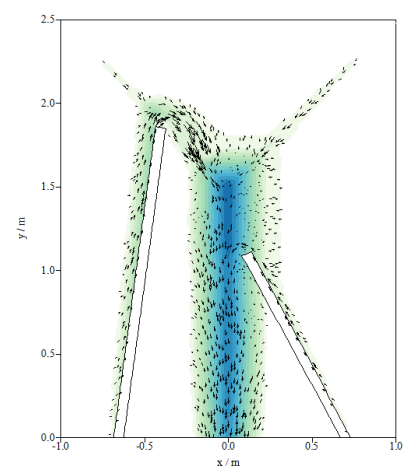

(a) case $1(\mathrm{t}=50 \mathrm{~s})$

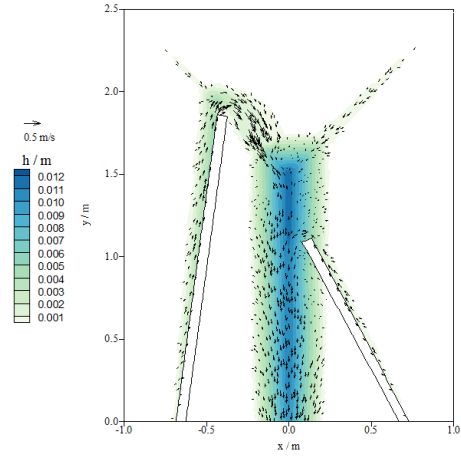

(b) case $2(\mathrm{t}=60 \mathrm{~s})$

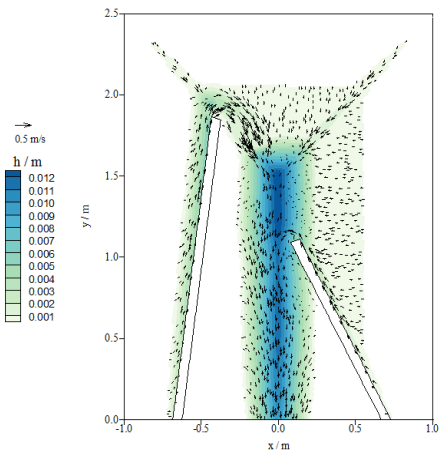

(c) case $\mathrm{c}(\mathrm{t}=60 \mathrm{~s})$

Figure 5: Water depth distribution and velocity fields

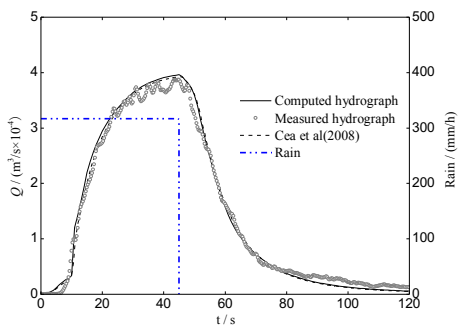

(a) case 1

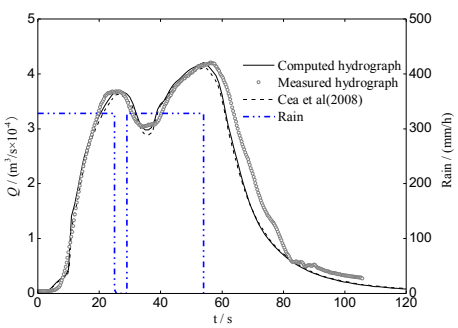

(b) case 2

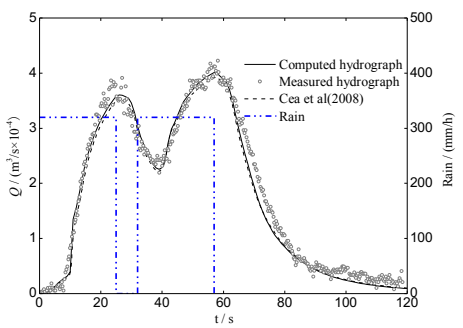

(c) case 3

Figure 6: Numerical hydrographs in the $2 \mathrm{D}$ verification test

\subsection{Two-dimensional Test Case with Complex Terrain and Varied Roughness}

The research domain is a $500 \mathrm{~m} \times 400 \mathrm{~m}$ sloping plane and the slopes of the plane in the $\mathrm{x}$ and $\mathrm{y}$ directions are $S_{o x}=0.02+0.0000149 x, S_{o y}=0.05+0.0000116 y$. In addition, Manning's roughness coefficient is $n=\sqrt{(0.1-0.0000168 x)^{2}+(0.1-0.0000168 y)^{2}}$. An unsteady uniform rainfall rate in the duration $200 \mathrm{~min}$ is given by a triangular hyetograph defined by $r(0)=r(200)=0 \mathrm{~mm} / \mathrm{min}$ and the peak rainfall is $r(100)=0.48 \mathrm{~mm} / \mathrm{min}$. The simulation time for this scenario was $240 \mathrm{~min}$. The initial condition is taken as $q=h=0$ at $t=0$ for all $x$ and $y$. The boundary conditions are $q=h=0$ at $x=0$ and $y=0$ for all $t$.

Total 908 triangular meshes are used to discretise the domain, and the $\mathrm{x}, \mathrm{y}$ boundaries are uniformly divided and controlled by $\triangle x=25 \mathrm{~m}$ and $\triangle y=20 \mathrm{~m}$, respectively. Since there is no analytical solution for this test case, the results obtained by Jaber \& Mohtar(2003) [14] and Tsai \& Yang( 2005) [15] are used to validate the presented numerical results. Fig.7 compares the simulated hydrograph at the outlet node of coordinates of $(500 \mathrm{~m}, 400 \mathrm{~m})$ produced by three different models. Good agreement is achieved by the present model though a slight discrepancy has been found in the peak discharge, which is probably due to the fact that different governing equations, numerical schemes and different meshes are used in the three models. 


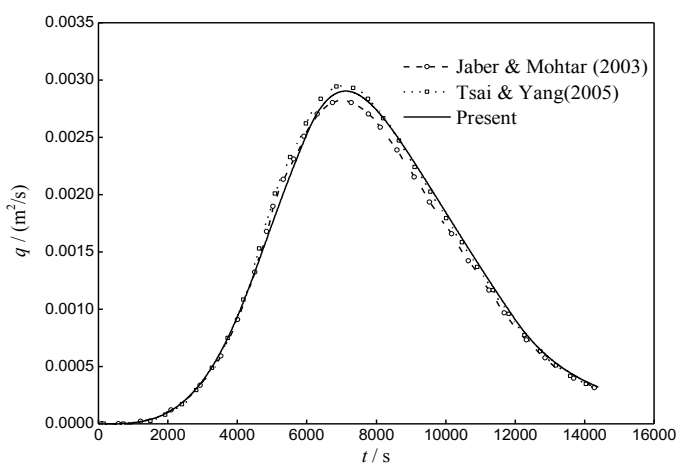

Figure 7: Simulated hydrograph at the outlet node of coordinates of $(500 \mathrm{~m}, 400 \mathrm{~m})$

\section{Conclusions}

This paper developed a new numerical model for simulating overland flow using fully dynamic shallow water equations based on the unstructured finite volume method. The sheet flow regime is used when calculating the numerical flux and discretizing the bottom slope source terms. In order to reduce the numerical instability induced by very shallow water depth often occurred in overland flows, the semi-implicit scheme is used to deal with the slope friction source terms. This twodimensional numerical model allows a direct transformation of the rainfall into the runoff hydrograph at the catchment outlet. The model has been verified by reproducing the analytical and experimental results in one-dimensional and two-dimensional situations and the results prove that it has more comprehensive calculation capabilities and good robust performances. In the future research, the model will be used to simulate the rainfall-runoff process of the real natural catchment to validate its practicability.

\section{Acknowledgement}

The research reported herein is funded by the National Key R\&D Program of China (2017YFC1502602), the National Natural Science Foundation of China (No.51509263), and the IWHR Research \& Development Support Program (JZ0145B772017).

\section{References}

[1] P. Costabile, C. Costanzo, F. Macchione, Comparative analysis of overland flow models using finite volume scheme, Journal of hydroinformatics. 14(2012) 122-135.

[2] L. Cea and E Blade, A simple and efficient unstructured finite volume scheme for solving the shallow water equations in overland flow applications, Water resources research. 51(2015) 54645486.

[3] X. Xia, Q. Liang, X. Ming, J. Hou, An efficient and stable hydrodynamic model with novel source term discretization schemes for overland flow and flood simulations, Water resources research. 53(2017) 3730-3759. 
Numerical Simulation of Overland Flows Using Godunov Scheme Based on Finite ... D. Zhang, et al.

[4] J. Murillo, P. Garcia-Navarro, Weak solutions for partial differential equations with source terms: application to the shallow water equations, Journal of computational physics.229(2010) 43274368.

[5] A. Lacasta, M. Morales-Hernandez, J. Murillo, et al, GPU implementation of the 2D shallow water equations for the simulation of rainfall/runoff events, Environment Earth Science. 74(2015) 7295-7305.

[6] C. Yu, J. Duan, Simulation of surface runoff using hydrodynamic model, Journal of hydrologic engineering. 22(2017) 0417006(1-12).

[7] P. Costabile, C. Costanzo, F. Macchione, A storm event watershed model for surface runoff based on 2D fully dynamic wave equations, Hydrological processes. 27(2013) 554-569.

[8] J.Kim, A. Warnock, V.Y.Ivanov, et al, Coupled modeling of hydrologic and hydrodynamic processes including overland and channel flow, Advances in water resources.37(2012) 104-126.

[9] A. Warnock, J. Kim, V. Ivanov, et al, Self-Adaptive kinematic-dynamic model for overland flow, Journal of hydraulic engineering. 140(2014) 169-181.

[10] R. S. Govindaraju, M. L. Kavvas, S. E. Jones, Approximate analytical solutions for overland flows, Water resources research. 26(1990) 2903-2912.

[11] G. Gottardi, M. Venutelli. An accurate time integration method for simplified overland flow models, Advances in Water resources. 31(2008) 173-180.

[12] D. F. Liang, I. Ozgen, R. Hinkelmann, et al, Shallow water simulation of overland flows in idealized catchments, Environmental Earth Sciences. 74(2015) 7307-7318.

[13] L. Cea, J. Puertas, L.Pena and M. Garrido, Hydrologic forecasting of fast flood events in small catchments with a 2D-SWE model, numerical model and experimental validation. World Water Congress 2008, Montpellier,France, Sep. 2008.

[14] F. H. Jaber and R. H. Mohtar, Stability and accuracy of two-dimensional kinematic wave overland flow modeling, Advances in water resources. 26(2003):1189-1198.

[15] T. L. Tsai and J. C. Yang, Kinematic wave modeling of overland flow using characteristics method with cubic-spline interpolation, Advances in water resources. 28(2005):661-670. 